\title{
Amplified Spontaneous Emission (ASE) Properties of a laser dye (LD-473) in solid state
}

\author{
K.H. Ibnaouf ${ }^{1,2^{*}}$, Kamal K. Taha ${ }^{3,4}$, Hajo Idriss ${ }^{5,6}$ and O. Aldaghri ${ }^{1}$
}

\begin{abstract}
The spectral characteristics of 1,2,3,8-tetrahydro-1,2,3,3,8-pentamethyl-5-(trifluoromethyl)-7H-pyrrolo[3,2-g]quinolin-7one (LD-473) were demonstrated in liquid and solid states. For the liquid state, the absorption and fluorescence spectra of the LD-473 in Methyl Methacrylate showed bands at 385 and 420 nm, respectively. LD-473 in the solid state showed one absorption band at $530 \mathrm{~nm}$, while the fluorescence spectra, under low concentration, showed one band at $615 \mathrm{~nm}$. For higher concentrations, the fluorescence bands are shifted to the red. LD-473 in the solid state under an impulse of Nd: YAG laser showed dual amplified spontaneous emission (ASE) peaks at 605 and $650 \mathrm{~nm}$. The longer wavelength coincided with a fluorescence peak while the shorter wavelength is an abnormal peak.
\end{abstract}

Keywords: Dye LD-473, Spectral properties, ASE, Solid state

\section{Introduction}

LD-473 is a type of laser dyes usually used to produce lasers light in the visible and infrared region of the spectrum [1-4]. When organic dyes like coumarins or rhodamines series dissolved in organic solvents and optically excited by laser source, the dye molecules strongly absorb the incident photons and emit high intense laser due to population inversion [5-8]. If the population inversion is very high, the optical gain should be so high and more enough to produce amplified spontaneous emission (ASE). ASE is a mirrorless laser without feedback, and is totally dependent on the active medium, as in coumarin and rhodamine laser dyes. However, any medium produced an ASE, has an ability to exhibit laser, although the reverse is not true $[5,9,10]$. Number of researches was done on rhodamine dye-doped polymers [8, 11-13]. A meager works have been done on blue green emitting solid-state dye lasers. The main purpose of this paper is to give an insight about the photophysical properties of a LD-473 in solution. Previously,

\footnotetext{
* Correspondence: kheo90@gmail.com

${ }^{1}$ College of Science, Physics Department, Al Imam Mohammad Ibn Saud Islamic University (IMSIU), P.O.Box 90950, Riyadh 11623, Saudi Arabia

${ }^{2}$ Alneelain University, School of Physics, Faculty of Science and Technology,

P.O. Box 12702, 11121 Khartoum, Sudan

Full list of author information is available at the end of the article
}

we had been tried to observe this phenomenon in some other laser coumarin dyes in solutions. All these coumarin dyes exhibited superexciplex formation under suitable concentrations and pump pulse energies. In this work, the spectral and ASE properties of LD-473 in solution and solid states were investigated. The absorption, fluorescence and ASE properties of LD-473 in solution and solid states depended on the concentrations, solvent environments and pump pulse energies. When the pump pulses excitation (Nd: YAG laser of 355 or $532 \mathrm{~nm}$ ) and the concentrations were suitably chosen, LD-473 showed an ASE around $475 \mathrm{~nm}$; while LD-473 in PMMA exhibited dual ASE peaks at 605 and $640 \mathrm{~nm}$, respectively.

\section{Experimental}

Methyl Methacrylate (MMA) and 2-hydoxyethyl methyl methacrylate (HMMA), dibenzoyl peroxide was obtained from Sigma-Aldrich and LD-473 from the Exciton Company was used in this work [14]. Solid-state rods with $7.0 \times 10^{-3}, 4.5 \times 10^{-3}$ and $1.8 \times 10^{-3} \mathrm{M}$ LD-473 were prepared by adding the exact masses of dye to 1:1 MMA to HMMA ratio. About $500 \mathrm{mg}$ of the initiator was then added and the mixture was stirred at $50{ }^{\circ} \mathrm{C}$ for $15 \mathrm{~min}$. The mixture was finally poured into a test tube of $1 \mathrm{~cm}$ 


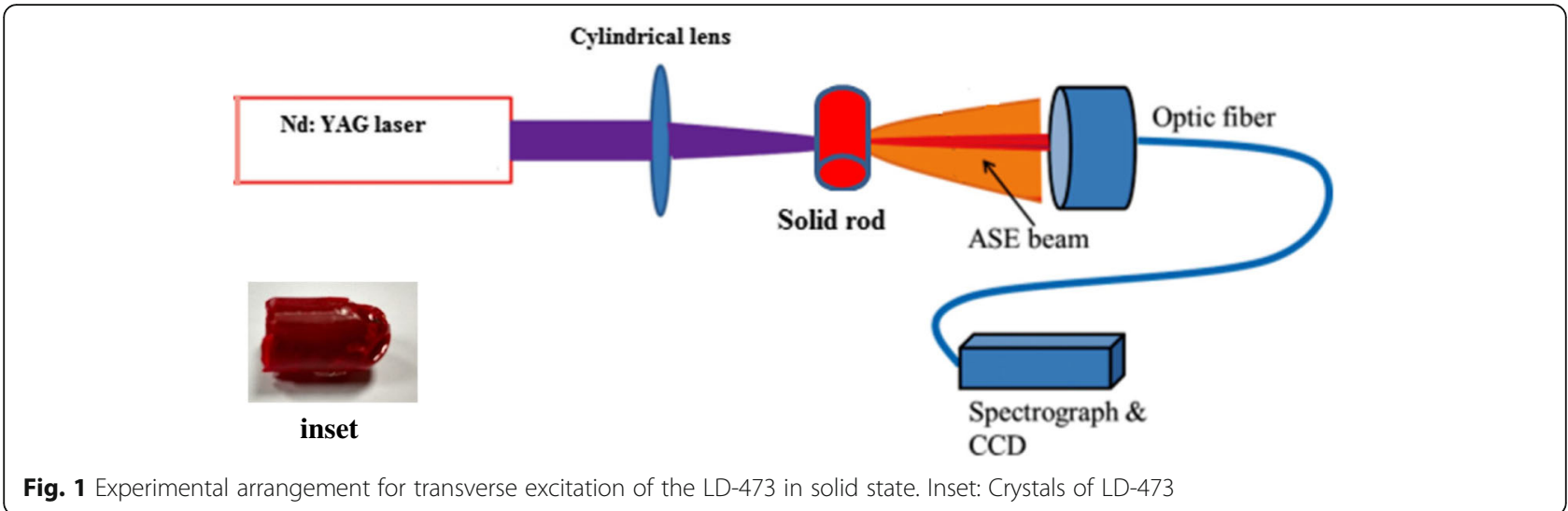

diameter and left for 2 days at room temperature. A bright red solid was formed (inset Fig. 1).

The absorption spectra were recorded for solid and liquid phases using a Perkin-Elmer lambda 950 spectrophotometer over the range from 100 to $1100 \mathrm{~nm}$. The solid samples in a form of solid rods were prepared under same dimensions and different concentrations, and the fluorescence spectra were recorded using a Perkin Elmer LS 55 spectrofluorometer which has a scan range of 200 to $1000 \mathrm{~mm}$, at room temperature. The excitation wavelengths were 355 and $532 \mathrm{~nm}$.

The ASE action was obtained by optically pumping the samples with an Nd: YAG laser emitting pulses at 355 and $532 \mathrm{~nm}$ with a $6 \mathrm{~ns}$ duration and $10 \mathrm{~Hz}$ repetition rate. A quartz cylindrical lens of focal length of $5 \mathrm{~cm}$ was used to focus the laser light beam. The focused pulse was transversely applied to excite the solid and liquid samples (Fig. 1). The cuvette was kept tilted for LD-473 in liquid state to avoid feedback $[15,16]$. At a suitable pump power, we could achieve an ASE beam which excited as a cone-shaped light. The emanated light was collected by a $1-\mathrm{mm}$ entrance slit of a spectrograph connected with a CCD camera to obtain the spectral features of the ASE.

\section{Results and discussions: \\ Spectral properties of LD-473}

The absorption spectra of LD-473 in solid state were recorded, with the dye concentrations from 1.8 to $7 \mathrm{mM}$. The absorption spectra showed only one band at $530 \mathrm{~nm}$ as shown in Fig. 2. On the other hand, the fluorescence spectrum of LD-473, at a concentration of $1.8 \mathrm{mM}$ showed a fluorescence band at $615 \mathrm{~nm}$. When the concentration increased, the fluorescence peak was red shifted. For example, at concentrations of 4.5 and $7 \mathrm{mM}$, the fluorescence bands were at 625 and $650 \mathrm{~nm}$, respectively as illustrated in Fig. 2. At concentrations higher than $7 \mathrm{mM}$, there was no significant red shift observed.

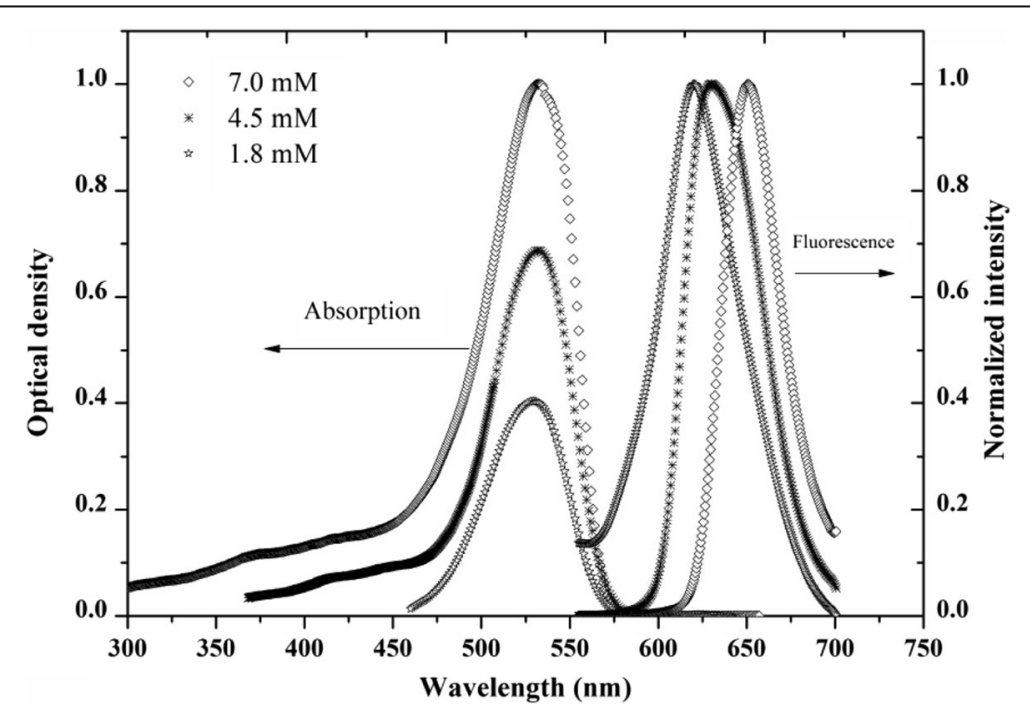

Fig. 2 Absorption and Fluorescence spectra of LD-473 solid state for different concentrations at an excitation wavelength of $532 \mathrm{~nm}$ 


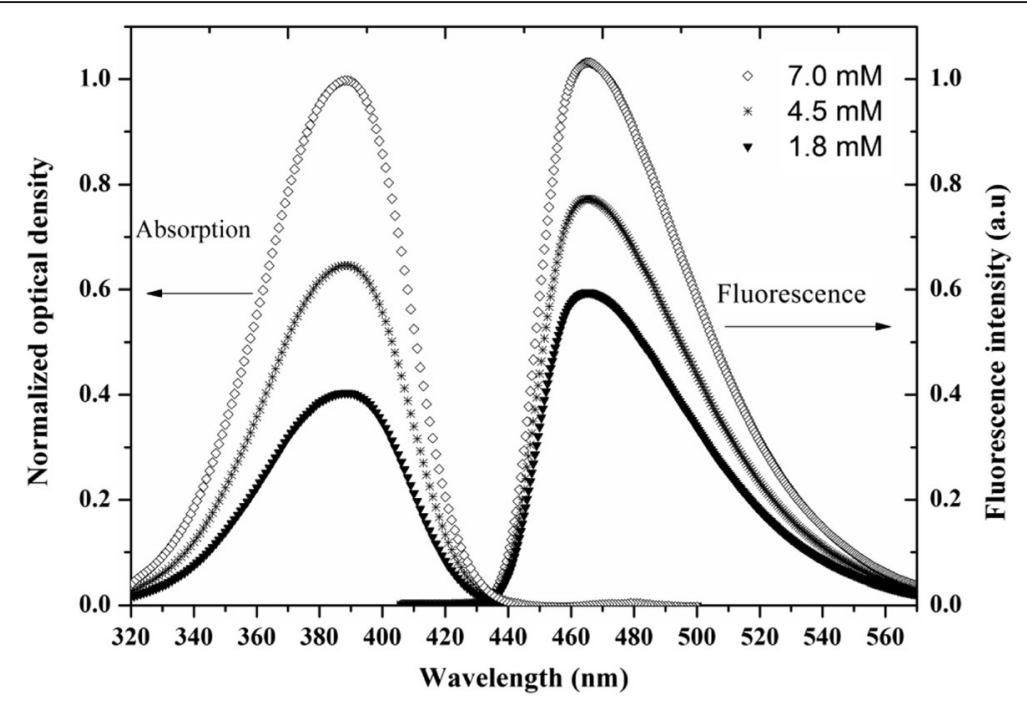

Fig. 3 Absorption and fluorescence spectra of LD-473 in MMA liquid state for different concentrations at an excitation wavelength of $355 \mathrm{~nm}$

Before the solidification, LD-473 in methyl methacrylate (MMA) was prepared. Figure 3 shows the absorption and fluorescence spectra of LD-473 for concentrations range from 1.8 to $7 \mathrm{mM}$. It was found that LD-473 has only one absorption band at $385 \mathrm{~nm}$. On the other hand, the fluorescence spectra of LD473 in MMA for all concentrations mentioned above showed only one band at $465 \mathrm{~nm}$ without changes in the shape of the fluorescence spectra.

\section{Florescence quantum yield}

The absorption and fluorescence spectra of LD-473 in different organic solvents were recorded. The fluorescence quantum yield ( $\Phi$ f) was measured using diluted solutions $(1.8 \mathrm{mM})$ to avoid reabsorption effect. The fluorescence quantum yield ( $\mathrm{ff}$ ) was calculated using the Eq. (1) [17]. It was found that the fluorescence quantum yield ( $\Phi f)$ around 0.72 .

$$
\Phi_{\mathrm{f}}(\mathrm{s})=\Phi_{\mathrm{f}}(\mathrm{r}) \frac{\mathrm{A}_{\mathrm{r}}}{\mathrm{A}_{\mathrm{s}}} \frac{\mathrm{n}_{\mathrm{s}}^{2}}{n_{\mathrm{r}}^{2}} \frac{\int \mathrm{F}_{\mathrm{s}}(\overline{\mathrm{v}}) \mathrm{d} \overline{\mathrm{v}}}{\int \mathrm{F}_{\mathrm{r}}(\overline{\mathrm{v}}) \mathrm{d} \overline{\mathrm{u}}}
$$

where the subscripts $\mathrm{s}$ and $\mathrm{r}$ refer to sample and reference; respectively, the integrals over $\mathrm{F}$ represent the area of the corrected fluorescence spectrum; $A$ is the absorbance value of the excitation wavelength; and " $n$ " the refractive index of the solvent.

Table 1 shows the strong dependence of $\Phi_{\mathrm{f}}$ on the absorption cross section $\left(\sigma_{\mathrm{a}}\right)$, stimulated emission cross section $\left(\sigma_{\mathrm{e}}\right)$, and extinction coefficient $\left(\epsilon_{\max }\right)[18]$

$$
\begin{aligned}
\sigma_{e} & =\frac{\lambda_{e}^{5} \Phi_{f}}{8 \pi c n^{2} \tau_{f}} \times \frac{I(\lambda)}{\int I(\lambda) d \lambda} \\
\sigma_{a} & =0.385 \times 10^{-20} \epsilon
\end{aligned}
$$

where $\boldsymbol{\lambda}$ is the wavelength, $\Phi_{f}$ is the quantum of the fluorescence, $\mathbf{n}$ is the index of refraction of the material, $\mathbf{c}$ is the speed of light in vacuum, $\mathbf{r}$ is the fluorescent lifetime of the upper laser level, $\mathrm{I}(\lambda)$ is the fluorescent intensity at wavelength $\lambda$, and $\epsilon$ is an extinction coefficient.

\section{ASE Spectrum of LD-473}

$1.8 \mathrm{mM}$ of LD-473, as solid state rod, was transversely excited using an Nd: YAG laser pulses $(532 \mathrm{~nm})$ with sufficient energy of $6 \mathrm{~mJ}$. Dual ASE peaks were observed in two narrow spectral regions; one at $605 \mathrm{~nm}$, as a shorter wavelength (SW), and at $640 \mathrm{~nm}$, as a longer wavelength peak $(\mathrm{LW})$ as shown in Fig. 4a. The intensity ratio recorded between SW and LW was 4:3. By increasing the concentration

Table 1 The photophysical parameters; Fluorescence quantum yield $\left(\phi_{f}\right)$, extinction coefficient $(\varepsilon)$, absorption cross section $\left(\sigma_{a}\right)$, emission cross section $\left(\sigma_{\mathrm{e}}\right)$, fluorescence lifetime $\left(\tau_{\mathrm{f}}\right)$, for LD-473 in different concentrations and matrixes

\begin{tabular}{llllll}
\hline LD-473 & Quantum Yield \% & $\varepsilon_{\max } \times 10^{5}(\mathrm{M} . \mathrm{cm})^{-1}$ & $\sigma_{\mathrm{a}} \times 10^{-15}\left(\mathrm{~cm}^{2}\right)$ & $\sigma_{e} \times 10^{-15}\left(\mathrm{~cm}^{2}\right)$ & 1.37 \\
\hline PMMA & 59.57 & 3.67 & 1.41 & 2.07 & 5.6 \\
MMA & 71.94 & 5.56 & 2.14 & 5.44 & 4 \\
Ethanol & 93.3 & 22.22 & 8.55 & $\mathrm{~T}$ & 3.5 \\
\hline
\end{tabular}




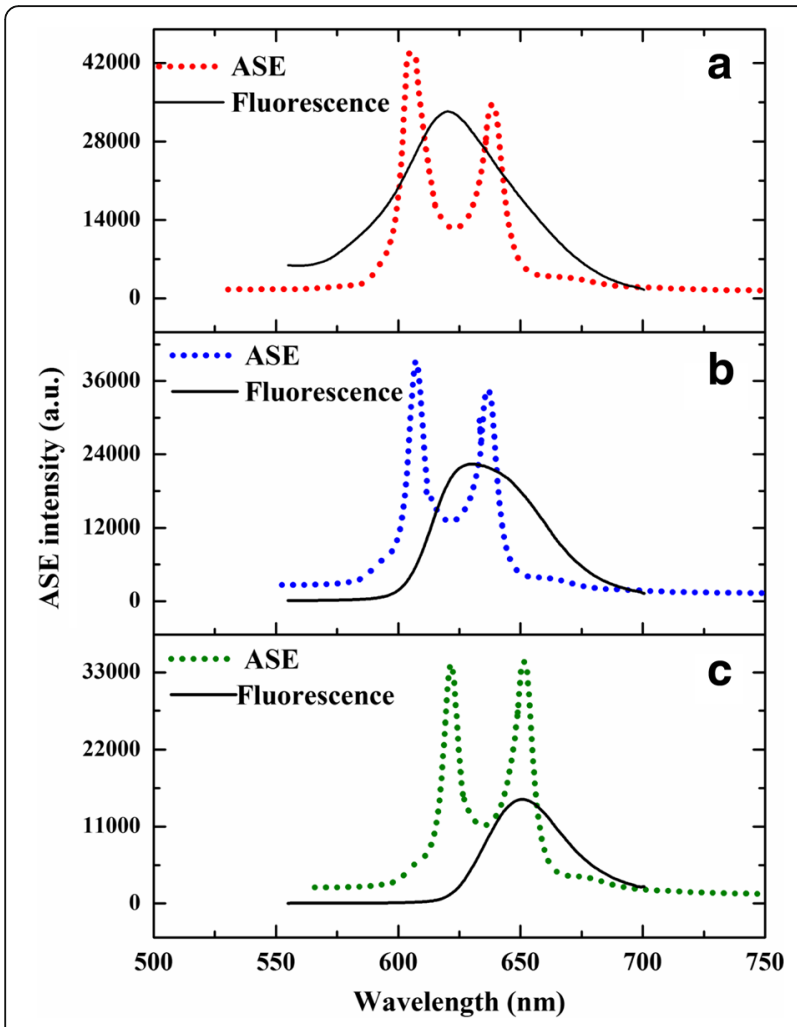

Fig. 4 ASE intensities of LD-473 solid state for at an excitation wavelength of $532 \mathrm{~nm}$ for concentrations of (a)1.8 mM (b) $4.5 \mathrm{mM}$ (c) $7 \mathrm{mM}$

to $4.5 \mathrm{mM}$, the intensity ratio was changed to $4: 3.6$ (Fig. $4 \mathrm{~b}$ ). One can immediately observe a small red shift in the SW band. Further increase in the concentration to $7 \mathrm{mM}$; the ASE peaks were almost comparable as shown in Fig. 4c. Moreover, there was a large red shift observed for the SW and LW to 621 and $650 \mathrm{~nm}$, respectively. It is important to note that corresponding to ASE around $650 \mathrm{~nm}$, there is a fluorescence band around $650 \mathrm{~nm}$, but there is no fluorescence band corresponding to ASE at $621 \mathrm{~nm}$ (see Figs. 4c and 2). It can be seen that, when the concentration was increased, the ASE intensity quenched due to the intermolecular interaction $[19,20]$ the ASE intensity was changed inversely with the concentration.

LD-473 in MMA at a concentration of $1.8 \mathrm{mM}$ was studied under identical operating conditions. This was the minimum concentration for LD-473 to produce an ASE spectrum. Figure 5 shows an ASE peak around $475 \mathrm{~nm}$. This peak is corresponding to the fluorescence band at $465 \mathrm{~nm}$. For higher concentrations, there was no change in the ASE features (Table 2).

Here, the optical and laser properties of LD-473 showed a large red shift after solidification; while in the previous studies, no shift appears in the spectrum after solidification $[5,21,22]$.

When $1.8 \mathrm{mM}$ of LD-473 as solid state was excited by $\mathrm{Nd}$ : YAG laser pulse of $6 \mathrm{~mJ}$ pulse energy, it gives ASE

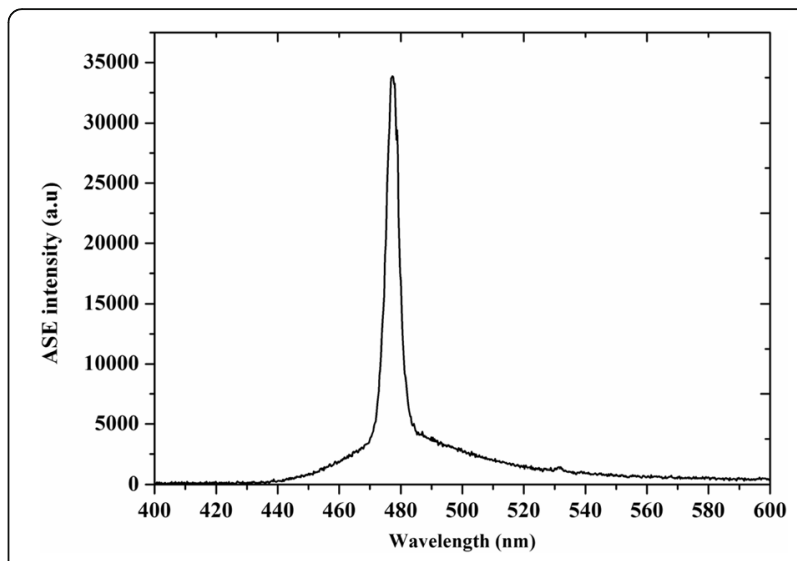

Fig. 5 ASE intensities of LD-473 in MMA liquid state at an excitation wavelength of $355 \mathrm{~nm}$ for a concentration of $1.8 \mathrm{mM}$

emission. The optical gain coefficient $(\gamma)$ of LD-473 was calculated using measuring the intensity of ASE intensity for two lengths of excitation $l_{1}=1 \mathrm{~cm}$ and $l_{2}=0.5 \mathrm{~cm}$ according to the following relation $[23,24]$ :

$$
\gamma(\lambda)=\frac{2}{L} \operatorname{Ln}\left(\frac{I_{l 1}}{I_{l 2}}-1\right)
$$

where, where $\mathrm{L}$ is the length of the irradiated dye in PMMA matrix rod, $I_{11}$, and $I_{12}$ are the intensities of ASE at lengths of $l_{1}$ and $l_{2}$, respectively.

Figure 6 illustrates the gain of LD-473 in solid state for different concentrations. For a length (L) of $10 \mathrm{~mm}$, repetition rate of $10 \mathrm{~Hz}$ and pump pulse energy of $6 \mathrm{~mJ}$, the gain $(\gamma)$ was found to be concentration dependent where the optimum gain per unit length was $4.4 \mathrm{~cm}^{-1}$ for the concentration of $7 \mathrm{mM}, 3.5 \mathrm{~cm}^{-1}$ for $4.5 \mathrm{mM}$ and $2.8 \mathrm{~cm}^{-1}$ for $1.8 \mathrm{mM}$.

\section{Conclusion}

In this paper, the spectral characteristics of LD-473 in the liquid state showed only one fluorescence band in the blue region. After solidification, the optical and ASE spectra were totally changed. It could be seen that the

Table 2 The photophysical parameters; absorption peak. $\left(\lambda_{\mathrm{a}}\right)$, fluorescence peak. $\left(\lambda_{f}\right)$ and wavelength max of laser emission $\left(\lambda_{L}\right)$, for LD-473 in different concentrations and matrixes

\begin{tabular}{|c|c|c|c|c|c|c|}
\hline \multirow[t]{2}{*}{ LD-473 } & \multirow{2}{*}{$\begin{array}{l}\text { Concentration } \\
(\mathrm{mM})\end{array}$} & \multirow{2}{*}{$\begin{array}{l}\lambda_{\mathrm{a}} \\
(\mathrm{nm})\end{array}$} & \multirow{2}{*}{$\begin{array}{l}\lambda_{f} \\
(n m)\end{array}$} & \multicolumn{2}{|c|}{$\lambda I(n m)$} & \multirow[t]{2}{*}{$\left(\frac{I_{S W}}{I_{L W}}\right)$} \\
\hline & & & & SW & LW & \\
\hline \multirow[t]{3}{*}{ PMMA } & 1.8 & 530 & 615 & 605 & 640 & 1.33 \\
\hline & 4.5 & 530 & 625 & 605 & 640 & 1.11 \\
\hline & 7 & 530 & 650 & 605 & 640 & 1.00 \\
\hline MMA & 1.8 & 408 & 465 & 471 & - & \\
\hline Ethanol & 1.8 & 390 & 440 & 473 & - & - - \\
\hline
\end{tabular}




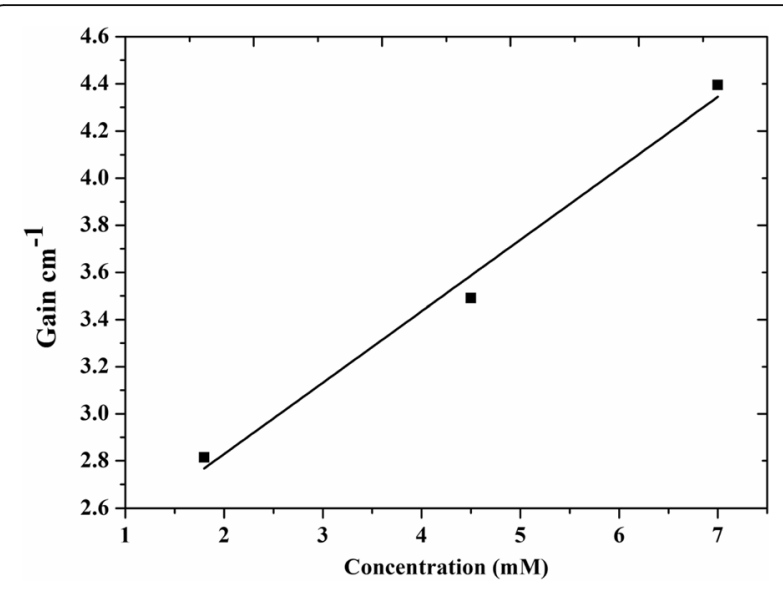

Fig. 6 The gain as a function of laser dyes concentration

whole spectrum was shifted to the red by $180 \mathrm{~nm}$. Moreover, anomalous ASE band at $605 \mathrm{~nm}$ was observed. The ASE band at $650 \mathrm{~nm}$ coincides with fluorescence at steady state, while the ASE band at $605 \mathrm{~nm}$ is an abnormal peak.

\section{Funding}

All funding for procurement of chemicals and conducting analysis were contributed by the authors.

\section{Availability of data and materials}

None.

\section{Authors' contributions}

K.K. Taha and K.H. Ibnaouf designed the experiments; K.K. Taha, Hajo Idriss and K.H. Ibnaouf performed the experiments; K.H. Ibnaouf and K.K. Taha analyzed the data; K.H. Ibnaouf, K.K. Taha and Hajo Idriss and Aldaghri wrote and revised the paper. All authors read and approved the final manuscript.

\section{Ethics approval and consent to participate}

None.

\section{Consent for publication}

None.

\section{Competing interests}

The authors declare that they have no competing interests

\section{Publisher's Note}

Springer Nature remains neutral with regard to jurisdictional claims in published maps and institutional affiliations.

\section{Author details}

${ }^{1}$ College of Science, Physics Department, Al Imam Mohammad Ibn Saud Islamic University (IMSIU), P.O.Box 90950, Riyadh 11623, Saudi Arabia. ${ }^{2}$ Alneelain University, School of Physics, Faculty of Science and Technology, P.O. Box 12702, 11121 Khartoum, Sudan. ${ }^{3}$ College of Science, Chemistry Department, Al Imam Mohammad Ibn Saud Islamic University (IMSIU), P.O.Box 90950, Riyadh 11623, Saudi Arabia. ${ }^{4}$ College of Applied \& Industrial Sscience, University of Bahri, Khartoum, Sudan. ${ }^{5}$ Al Imam Mohammad Ibn Saud Islamic University (IMSIU), College of Science, Committee on Radiation and Environmental Pollution Protection, Riyadh, KSA, Saudi Arabia. ${ }^{6}$ Ministry of Higher Education \& Scientific Research, Sudan Atomic Energy Commission, Khartoum, Sudan.
Received: 14 June 2017 Accepted: 9 August 2017

Published online: 22 August 2017

\section{References}

1. Deepa, H., et al.: Solvatochromic shift studies in LD-425 and LD-423: Estimation of ground and excited state dipole moments. J. Mol. Liq. 181 82-88 (2013)

2. Masilamani, V., Sivaram, B.: Spectral and laser gain characteristics of solvated species of scopoletin. J. Lumin. 22(2), 211-220 (1981)

3. Porter, G., Suppan, P.: Primary photochemical processes in aromatic molecules. Part 12.-Excited states of benzophenone derivatives. Trans. Faraday Soc. 61, 1664-1673 (1965)

4. Olivares, S.P., Risso, S., Gutierrez, M.l.: Solvent effects on the spectroscopic properties of 4-hexylresorcinol. Spectrochim. Acta A Mol. Biomol. Spectrosc. 71(2), 336-339 (2008)

5. Ibnaouf, $\mathrm{K}$, et al.: Amplified spontaneous emission spectra from the superexciplex of coumarin 138. Spectrochim. Acta A Mol. Biomol. Spectrosc. 97, 1145-1151 (2012)

6. Zhang, D., et al.: Low threshold amplified spontaneous emission based on coumarin 151 encapsulated in mesoporous SBA-15. Appl. Phys. Lett. 89(23), 231112 (2006)

7. Sastikumar, D. and V. Masilamani. Influence of solvents on amplified spontaneous emission characteristics of 7-diethylamino-4-methylcoumarin. in Proceedings of the Indian Academy of Sciences-Chemical Sciences. Springer, India (1997)

8. Somasundaram, G., Ramalingam, A.: Gain studies of Coumarin 1 dye-doped polymer laser. J. Lumin. 90(1), 1-5 (2000)

9. Ibnaouf, K., et al.: Dual ASE Spectra from" Superexciplex" TICT States of Dye Molecules. Laser Phys Lawrence. 15(11), 1536 (2005)

10. Ibnaouf, $K$.: Effects of the solvent environments on the ASE from coumarin 503. Optik-Int J Light Electron Opt. 126(24), 5057-5060 (2015)

11. Guli, M., et al.: Encapsulation of Coumarin 151 into the mesopores of modified rodlike SBA-15. Mater. Res. Bull. 45(1), 1-5 (2010)

12. Ferrer, M., et al.: Proton-transfer lasers from solid polymeric chains with covalently bound 2-(2'-hydroxyphenyl) benzimidazole groups. Appl. Opt. 33(12), 2266-2272 (1994)

13. Canva, M., et al.: Perylene-and pyrromethene-doped xerogel for a pulsed laser. Appl. Opt. 34(3), 428-431 (1995)

14. Exciton, LD-473 Available from: http://www.exciton.com/pdfs/ld473.pdf

15. Ibnaouf, K.: Laser from external energy transfer of MEH-PPV conjugated polymer. Opt. Laser Technol. 44(3), 710-713 (2012)

16. Idriss, $H_{\text {., }}$ et al:: Amplified spontaneous emission from the exciplex state of a conjugated polymer "PFO" in oleic acid. Opt. Laser Technol. 83, 148-152 (2016)

17. Mahaney, M., Huber, J.R.: Fluorescence from the second excited singlet of aromatic thioketones in solution. Chem. Phys. 9(3), 371-378 (1975)

18. Moulton, P.F.: Spectroscopic and laser characteristics of Ti: Al 2 O 3. JOSA B. $3(1), 125-133(1986)$

19. Bondarev, S., et al.: Fluorescence and electronic structure of the laser dye DCM in solutions and in polymethylmethacrylate. J. Appl. Spectrosc. 71(2), 194-201 (2004)

20. Yao, Y.S., et al.: Starburst DCM-Type Red-Light-Emitting Materials for Electroluminescence Applications. Adv. Funct. Mater. 16(5), 709-718 (2006)

21. Costela, A., et al.: Solid-state dye laser based on Coumarin 540A-doped polymeric matrices. Opt. Commun. 130(1), 44-50 (1996)

22. Singh, S., et al.: Solid-state polymeric dye lasers. J. Lumin. 101(4), 285-291 (2003)

23. del Valle, J.C., Kasha, M., Catalán, J.: Spectroscopy of Amplified Spontaneous Emission Laser Spikes in Phenyloxazoles. Prototype Classes. J. Phys. Chem. A. 101(18), 3260-3272 (1997)

24. Al-Shamiri, H.A.S., Y. Badr, and M.T.A. Kana. Optical, Photo-physical properties and photostability of laser dyes impregnated in Sol-Gel matrix. in Electronics, Communications and Photonics Conference (SIECPC), 2011 Saudi International. IEEE, Saudi (2011) 